\title{
Treating genitourinary and pharyngeal gonorrhoea with single dose ceftriaxone
}

\author{
J CHRISTOPHERSEN,* A C BOLLERUP, † E FROM, J O RØNNE-RASMUSSEN,§ \\ K QUITZAU\|
}

From the *Department of Dermatovenereology, Gentofte Hospital, Hellerup; the $\dagger$ Neisseria Department, Statens Seruminstitut, Copenhagen; the $\ddagger$ Department of Dermatovenereology, Marselisborg Hospital, Aarhus; the §Department of Dermatovenereology, Bispebjerg Hospital, Copenhagen; and the ||Department of Clinical Research, Roche, Denmark

SUMMARY The efficacy of ceftriaxone $250 \mathrm{mg}$ given as a single intramuscular dose to treat genitourinary and pharyngeal gonorrhoea is compared with the outcome of the Danish standard treatment for uncomplicated genitourinary gonorrhoea, pivampicillin $1.4 \mathrm{~g}$ and probenecid $1 \mathrm{~g}$, both given by mouth.

The study comprised 327 patients for whom the diagnosis of gonorrhoea was made by microscopy of a methylene blue stained smear at their first visit to the clinic and for whom the diagnosis was later confirmed by culture of Neisseria gonorrhoeae.

One hundred and seventy patients with genitourinary gonorrhoea (18 with and 152 without concomitant pharyngeal infection) were treated with ceftriaxone. One hundred and fifty seven (17 with and 140 without concomitant pharyngeal infection) were treated with pivampicillin. One week after treatment $N$ gonorrhoeae was isolated from none of 18, 1/152, (1\%), 11/17 (65\%), and 6/140 (4\%) patients, respectively. At a second attendance two weeks after treatment no further treatment failure was found.

During the study period, a further 52 patients with pharyngeal infection (with or without concomitant genitourinary infection) that was shown by culture only were treated with a single intramuscular injection of $250 \mathrm{mg}$ ceftriaxone. No treatment failure was observed in this group.

Only minor adverse drug reactions were seen.

Ceftriaxone $250 \mathrm{mg}$ as a single intramuscular injection is therefore safe and effective in treating gonorrhoea, including pharyngeal infection.

In some parts of the world single dose regimens of penicillin and probenecid for treating uncomplicated genitourinary gonorrhoea can still be recommended.' The increasing prevalence of penicillinase producing strains of Neisseria gonorrhoeae (PPNG), strains with chromosomally mediated resistance, and spectinomycin resistant strains, have stressed the need for alternative treatment regimens. ${ }^{2}$ Moreover, single dose antibiotic regimens have so far been unsatisfactory for treating pharyngeal gonorrhoea. ${ }^{34}$

Ceftriaxone, a new extended range cephalosporin, is one of the most active of all antimicrobial agents

Address for reprints: Dr J Christophersen, Department of Dermatovenereology, Gentofte Hospital, DK-2900 Hellerup, Denmark

Accepted for publication 17 August 1988 against $N$ gonorrhoeae, and has minimum inhibitory concentrations (MICs) within the range 0.0004-0.03 $\mu \mathrm{g} / \mathrm{ml} .{ }^{56}$ This exceptional activity, combined with high blood concentrations, pronounced tissue penetration, and a plasma half life of eight hours, make it particularly favourable for treating gonorrhoea.

Clinical trials using single doses of $125-250 \mathrm{mg}$ ceftriaxone have produced cure rates of $100 \%$ in uncomplicated gonorrhoea in men and women. ${ }^{6-9}$ The effect of single dose ceftriaxone in pharyngeal gonorrhoea is not well known, but results obtained by Judson et al were promising. A single intramuscular dose of $125 \mathrm{mg}$ ceftriaxone cured $30(93.8 \%)$ of 32 pharyngeal infections. ${ }^{10}$

The present study aimed to evaluate the efficacy of a single dose regimen of $250 \mathrm{mg}$ ceftriaxone in pharyngeal gonorrhoea and to compare the cure rate and the 
acceptability of ceftriaxone with those of our standard initial treatment of non-PPNG infections acquired in Denmark ( $1.4 \mathrm{~g}$ pivampicillin by mouth given with $1 \mathrm{~g}$ probenecid).

\section{Patients and methods}

The study was undertaken as an open randomised comparative multicentre study. All patients aged over 18 who attended the clinics during March 1986 to February 1987 were invited to participate. We included patients who gave their informed consent and for whom a diagnosis of genitourinary or rectal gonorrhoea was made by microscopy of a methylene blue stained smear at the initial visit. Patients were excluded if they had received antibiotics in the previous seven days, if they had known or suspected hypersensitivity to cephalosporins, penicillins, or lidocaine or if they had known renal or hepatic insufficiency.

A total of 393 patients were randomised to treatment with either ceftriaxone $250 \mathrm{mg}$ given as an intramuscular injection or pivampicillin $1.4 \mathrm{~g}$ plus probenecid $1 \mathrm{~g}$ given by mouth. Before treatment specimens were taken for culture as follows: one each from the urethra and the rectum and two from the tonsillar region of each patient; an additional specimen was taken from the cervix of each woman. Patients for whom the cultures for $\mathrm{N}$ gonorrhoeae were negative were subsequently excluded from the study.

Follow up visits were planned on days 7 and 14 after treatment. On each occasion specimens were taken for culture. If gonococci persisted or reappeared within 14 days after treatment and the patient had not had further sexual intercourse, the treatment was considered to have failed. The reappearance of gonococci after negative cultures on two occasions was considered to be due to reinfection irrespective of the patient's history.

During the study period a further 52 patients with pharyngeal infection with or without concomitant genitourinary or rectal infection, which was shown only by culture, were treated with a single intramuscular injection of $250 \mathrm{mg}$ ceftriaxone. The schedule for control visits and cultures was similar to that for the first 393 patients.

\section{CULTURE OF N GONORRHOEAE}

Specimens were transported from the clinics to the laboratories on charcoal impregnated sterile wooden applicators in a modified Stuart's medium. Each swab was streaked on a selective chocolate agar medium containing amphotericin B $(2 \mu \mathrm{g} / \mathrm{ml})$, polymyxin B sulphate $(25 \mathrm{IU} / \mathrm{ml})$, lincomycin $(1 \mu \mathrm{g} / \mathrm{ml})$, and trimethoprim lactate $(3 \mu \mathrm{g} / \mathrm{ml})$. Gonococcus like oxidase positive colonies were identified by a direct immunofluorescence test or carbohydrate (glucose, maltose, and sucrose) utilisation tests, or both and by a Gram stained smear.

IN VITRO SUSCEPTIBILITY TESTING

Susceptibility to ceftriaxone and penicillin was tested by a plate dilution method with twofold dilution steps of the antibiotics; the results are expressed as the minimum inhibitory concentrations (MICs). The concentrations of ceftriaxone ranged from 0.064 to $0.00025 \mu \mathrm{g} / \mathrm{ml}$ and for penicillin from 2.4 to 0.0094 $\mu \mathrm{g} / \mathrm{ml}$. Isolates requiring an MIC of penicillin of $1 \cdot 2$ $\mu \mathrm{g} / \mathrm{ml}$ or more were examined for the production of penicillinase by the chromogenic cephalosporin test.

During the study period, isolates from all patients attending two of the participating dermatovenereological outpatient clinics were stored in liquid nitrogen for susceptibility testing. From a third clinic, however, only isolates from patients who entered the study were stored.

\section{Results}

Table 1 shows the demographic characteristics of the study population. Of 393 patients enrolled in the study, $327(83 \%)$, whose diagnosis was confirmed by culture of $\mathbf{N}$ gonorrhoeae and who returned for the first follow up visit, constituted the final study population. Of the remaining 66 patients, 42 were excluded because $N$ gonorrhoeae was not isolated from the specimens taken at the initial visit, three were not treated according to the protocol, and 21 did not return for follow up.

The two treatment groups were comparable for age and sex. Genitourinary infection without pharyngeal infection was diagnosed in $243(90 \%)$ of 269 men and $49(84 \%)$ of 58 women. The remaining $26(10 \%)$ men

Table 1 Characteristics of the study population of 393 patients (figures are numbers (percentages) except where stated)

\begin{tabular}{lllll}
\hline & \multicolumn{3}{l}{ Treatment regimen } \\
\cline { 2 - 6 } & $\begin{array}{l}\text { Ceftriaxone } \\
250 \text { mg by } \\
\text { intramuscular } \\
\text { injection }\end{array}$ & $\begin{array}{l}\text { Pivampicillin } \\
1.4 \mathrm{~g} \text { and } \\
\text { probenecid } 1 \mathrm{~g} \\
\text { by mouth }\end{array}$ \\
\hline \begin{tabular}{lllll} 
No treated & 198 & 195 & \\
No evaluable* & 170 & $(86)$ & 157 & $(81)$ \\
$\begin{array}{l}\text { Sex distribution: } \\
\begin{array}{l}\text { Men } \\
\text { Women }\end{array}\end{array}$ & 143 & $(84)$ & 126 & $(80)$ \\
$\begin{array}{l}\text { Median (range) age (years): } \\
\text { Men } \\
\text { Women }\end{array}$ & 27 & $(16)$ & 31 & $(20)$ \\
\hline
\end{tabular} & 26 & $(18-63)$ & 27 & $(18-56)$ \\
\hline
\end{tabular}

*Patients for whom diagnosis was confirmed by culture of Neisseria gonorrhoeae and who returned for follow up. 
Table 2 Outcome of treatment with ceftriaxone or pivampicillin and probenecid in 327 patients with genitourinary gonorrhoea, 35 with and 292 without concomitant pharyngeal infection (figures are numbers (percentages) of patients not cured out of numbers treated)

\begin{tabular}{lllll}
\hline & Treatment regimen \\
\cline { 2 - 5 } Infection & $\begin{array}{l}\text { Ceftriaxone 250 g by } \\
\text { intramuscular injection }\end{array}$ & $\begin{array}{l}\text { Pivampicillin } 1.4 \mathrm{~g} \text { and } \\
\text { probenecid } 1 \mathrm{~g} \text { by mouth }\end{array}$ \\
\hline Genitourinary & $1 / 152$ & $(1)$ & $6 / 140$ & $(4)$ \\
Pharyngeal & $0 / 18$ & $(0)$ & $11 / 17$ & (65) \\
\hline
\end{tabular}

and nine $(6 \%)$ women also had pharyngeal gonorrhoea.

Table 2 shows that $151(99 \%)$ of 152 patients with uncomplicated genitourinary infection treated with ceftriaxone yielded negative cultures for $N$ gonorrhoeae compared with $134(96 \%)$ of 140 treated with pivampicillin. Concomitant pharyngeal gonococcal infection was eradicated in all 18 patients treated with ceftriaxone compared with six $(35 \%)$ of 17 patients treated with pivampicillin, a significant difference ( $p<0.05$, Fisher's exact test). Of five patients infected with PPNG strains, two had pharyngeal infection. All were treated with and cured by ceftriaxone.

Of the additional 52 patients with pharyngeal infection treated with ceftriaxone, seven were excluded from analysis of efficacy because of negative culture on the day of treatment and five did not return for follow up. These patients were similar to the main study population in sex and age. All 20 evaluable women and 20 evaluable men yielded negative cultures for $N$ gonorrhoeae after treatment. In 14 of the patients the evaluation was based on a positive culture from the pharynx on the day of treatment. In 26 the positive culture had been obtained within two weeks before treatment.

No serious adverse drug reactions were seen after treatment with either ceftriaxone or pivampicillin. Minor gastrointestinal complaints (mainly "loose stools" or diarrhoea) were experienced by more (10/
Table 4 Minimum inhibitory concentrations of penicillin for 17 strains of Neisseria gonorrhoeae isolated from patients with gonorrhoea not cured by treatment with pivampicillin $1.4 \mathrm{~g}$ plus probenecid $1 \mathrm{~g}$

\begin{tabular}{|c|c|c|c|}
\hline \multirow[b]{2}{*}{$\begin{array}{l}\text { MIC }(\mu \mathrm{g} / \mathrm{ml}) \\
\text { of penicillin }\end{array}$} & & \multicolumn{2}{|c|}{ No of isolates from: } \\
\hline & & $\begin{array}{l}\text { Genitourinary } \\
\text { infection }\end{array}$ & $\begin{array}{l}\text { Pharyngeal } \\
\text { infection }\end{array}$ \\
\hline $\begin{aligned}<0.15 \\
0.30-0.60\end{aligned}$ & $\begin{array}{l}\text { Susceptible } \\
\text { Less }\end{array}$ & 0 & 5 \\
\hline $1 \cdot 2-2 \cdot 40$ & $\begin{array}{c}\text { susceptible } \\
\text { Resistant }\end{array}$ & $\begin{array}{l}4 \\
2\end{array}$ & $\begin{array}{l}3 \\
3\end{array}$ \\
\hline
\end{tabular}

$170(6 \%))$ patients treated with ceftriaxone than by those $(3 / 157(2 \%))$ treated with pivampicillin and probenecid $(p=0.046)$.

A total of 805 gonococcal strains were tested for susceptibility to ceftriaxone and penicillin (table 3 ), 380 of them were from patients who entered the study. A strong positive correlation $(r=0.93)$ was seen except for PPNG strains. The ratios between the MICs of penicillin and of ceftriaxone were 1:40 for strains with MICs of penicillin of $0 \cdot 15 \mu \mathrm{g} / \mathrm{ml}$ or less and 1:80 for strains with MICs of penicillin of less than $0 \cdot 15 \mu \mathrm{g} /$ $\mathrm{ml}$. The MICs of ceftriaxone against isolates from the patient who was not cured after treatment with ceftriaxone were $0.002 \mu \mathrm{g} / \mathrm{ml}$ before and $0.004 \mu \mathrm{g} / \mathrm{ml}$ after treatment.

Table 4 shows the MICs of penicillin for strains isolated from patients who were not cured by treatment with pivampicillin $1.4 \mathrm{~g}$ and probenecid $1 \mathrm{~g}$. None of them were PPNG strains.

\section{Discussion}

The standard treatment of uncomplicated gonorrhoea (pivampicillin $1.4 \mathrm{~g}$ and probenecid $1 \mathrm{~g}$ by mouth) was successful in $96 \%$ of our patients. A similar cure rate was found in a study from Copenhagen in 1983, " and must be considered to be satisfactory. On the other hand, the standard regimen gave an unsatisfactory cure rate (only $35 \%$ ) for pharyngeal gonorrhoea as in

Table 3 Correlation between minimum inhibitory concentrations (MICs) of ceftriaxone and penicillin for 805 strains of Neisseria gonorrhoeae

\begin{tabular}{|c|c|c|c|c|c|c|c|}
\hline \multirow{2}{*}{$\begin{array}{l}\text { MIC }(\mu \mathrm{g} / \mathrm{ml}) \\
\text { of ceftriaxone }\end{array}$} & \multicolumn{5}{|c|}{ No of non-PPNG isolates with MICs $(\mu \mathrm{g} / \mathrm{ml})$ of penicillin of: } & \multirow{2}{*}{$\begin{array}{l}\text { No of } \\
\text { PPNG isolates }\end{array}$} & \multirow[b]{2}{*}{ Total } \\
\hline & $<0.01-0.04$ & $0.08-0.15$ & $0.30-0.60$ & $1 \cdot 2-2 \cdot 4$ & $>2.4$ & & \\
\hline $\begin{array}{l}<0.00025 \\
0.0005-0.001 \\
0.002-0.004 \\
0.008-0.016 \\
0.032-0.064 \\
0.128\end{array}$ & $\begin{array}{r}136 \\
252 \\
1 \\
0 \\
0 \\
0\end{array}$ & $\begin{array}{r}0 \\
5 \\
98 \\
19 \\
2 \\
0\end{array}$ & $\begin{array}{r}0 \\
2 \\
115 \\
58 \\
2 \\
0\end{array}$ & $\begin{array}{r}0 \\
0 \\
1 \\
58 \\
28 \\
0\end{array}$ & $\begin{array}{l}0 \\
0 \\
1 \\
0 \\
3 \\
1\end{array}$ & $\begin{array}{r}0 \\
0 \\
8 \\
13 \\
2 \\
0\end{array}$ & $\begin{array}{r}136 \\
259 \\
224 \\
148 \\
37 \\
1\end{array}$ \\
\hline Total & 389 & 124 & 177 & 87 & 5 & 23 & 805 \\
\hline
\end{tabular}

PPNG = penicillinase producing $N$ gonorrhoeae. 
previous studies. ${ }^{34}$ Our treatment failures were not associated with decreased sensitivity to penicillin in vitro (table 4).

Ceftriaxone as a single intramuscular dose of 250 mg was an effective treatment in men and women with uncomplicated gonorrhoea (including five patients infected with PPNG strains) and gave a cure rate of $99 \%$. This finding confirmed the results of other studies that showed $100 \%$ efficacy of single doses of $125-250 \mathrm{mg}$ ceftriaxone for uncomplicated gonorrhoea. $^{6-9}$

Single dose ceftriaxone $250 \mathrm{mg}$ was also highly effective in treating pharyngeal gonorrhoea. All 58 patients, including 26 who yielded positive cultures within two weeks before treatment and two infected with PPNG strains, were cured. Judson et al found 125 mg ceftriaxone to be effective in $30(94 \%)$ of 32 pharyngeal infections. ${ }^{10}$ This might indicate that a larger dose of $250 \mathrm{mg}$ ceftriaxone can improve the cure rate of single dose treatment of pharyngeal gonorrhoea, although the numbers were too small to give a significant difference. ( $95 \%$ Confidence levels were $79 \cdot 2-99 \cdot 2$ in the study by Judson et $\mathrm{l}^{10}$ and $93 \cdot 8-100 \cdot 0$ in our study).

Ceftriaxone is also superior to other single dose regimens for treating pharyngeal gonorrhoea. Treatment with spectinomycin $2 \mathrm{~g}$ or $4 \mathrm{~g}$ as a single dose had a cure rate of only $43-46 \%$ of the pharyngeal infections treated. ${ }^{10}{ }^{12} \mathrm{~A}$ similar low cure rate was found for two second generation cephalosporins, cefonicid and cefuroxime. ${ }^{1314}$

Epidemiological studies from the venereal diseases clinics in Copenhagen ${ }^{1516}$ and the Neisseria Department, Statens Seruminstitut ${ }^{17}$ during recent years have shown a constant incidence of pharyngeal gonorrhoea of $15 \%$ in patients examined for gonorrhoea, with the highest incidence in women and homosexual men. This indicates that pharyngeal gonorrhoea is a numerically important problem. The clinical importance and the contagiousness of pharyngeal gonorrhoea has not been satisfactorily assessed. The infection seems to give throat symptoms seldom, ${ }^{418} 19$ and may in some cases be self limiting. ${ }^{18}$ Pharyngeal gonorrhoea is thus a reservoir of $N$ gonorrhoeae. Until it is proved not to be contagious or a possible source of dissemination, therefore, patients with pharyngeal gonorrhoea should be treated.

\section{References}

1 WHO Expert Committee on Venereal Diseases and Treponematoses. Sixth Report. WHO Tech Rep Ser 1986; No 736:11823.

2 Centers for Disease Control. Antibiotic-resistant strains of Neisseria gonorrhoeae. MMWR 1987;36/5S1-18.

3 Washington AE. Update on treatment recommendations for gonococcal infections. Rev Infect Dis 1982;4suppl:758-71.

4 Bro-Jørgensen A, Jensen T. Gonococcal pharyngeal infections: report of 110 cases. British Journal of Venereal Diseases 1973; 49:491-2.

5 Ng WS, Chau PY, Ling J, Echeverria P, Rockhill R, Arnold K. Penicillinase-producing Neisseria gonorrhoeae isolates from different localities in south east Asia. British Journal of Venereal Diseases 1983;59:232-6.

6 Zajdowicz TR, Sanches PL, Berg SW, Kerbs SBJ, Newquist RL, Harrison WO. Comparison of ceftriaxone with cefoxitin in the treatment of penicillin-resistant gonococcal urethritis. British Journal of Venereal Diseases 1983;59:176-8.

7 Handsfield HH, Murphy VL. Comparative study of ceftriaxone and spectinomycin for treatment of uncomplicated gonorrhoea in men. Lancet 1983;ii:67-70.

8 Panikabutra K, Ariyarit C, Chitwarakorn A, Saensanoh C, Wongba C. Randomised comparative study of ceftriaxone and spectinomycin in gonorrhoea. Genitourin Med 1985;61:106-8.

9 Dixon CA, Bittiner JB, Shahidullah M, Slack RCB, Sulaiman MZC. Randomised observer blind comparative trial of ceftriaxone and penicillin in treating uncomplicated gonorrhoea in men and women. Genitourin Med 1986;62:78-81.

10 Judson FN, Ehret JM, Handsfield HH. Comparative study of ceftriaxone and spectinomycin for treatment of pharyngeal and anorectal gonorrhoea. JAMA 1985;253:1417-9.

11 Hagdrup H, Serup J. Treatment of gonorrhoea with a single dose of pivampicillin and failure to cure. Ugeskr Lager 1985;147: 1536-7.

12 Wiesner PJ, Tronca E, Bonin P, Pedersen AHB, Holmes KK. Clinical spectrum of pharyngeal gonococcal infection. $N$ Engl $J$ Med 1973;288:181-5.

13 Handsfield HH, Murphy VL. Treatment of uncomplicated gonorrhoea in women with single dose cefonicid. Sex Transm Dis 1985;12:90-2.

14 Graudal C, Bollerup AC, Lange K, Seier K, Lind I. The outcome of single-dose cefuroxime treatment in patients with pharyngeal gonorrhoea. Sex Transm Dis 1985;12:49-51.

15 Hagdrup H, Serup J. Tonsillar and rectal gonorrhoea. The value of routine culture for gonococci from tonsils and the rectum. Ugeskr Lager 1985;147:3607-9.

16 Worm AM, Fogh H, Petersen CS. The diagnosis and therapeutic control of gonorrhoea. The effects and costs. Ugeskr Lager 1986;148:2819-21.

17 Lind I, Bollerup AC, Gadeberg OV, Reimann K, Bentzon MW. Activities of the WHO collaborating centre for reference and research in gonococci, Copenhagen, for the year 1986. WHO/ VDT/RES/GON/87 1987;150:1-15.

18 Wallin J. Pharyngeal Neisseria gonorrhoeae: coloniser or pathogen? Br Med J 1979;i:1462-3.

19 Young H, Bain SSR. Neisserial colonisation of the pharynx. British Journal of Venereal Diseases 1983;59:228-31. 